University of Nebraska - Lincoln

DigitalCommons@University of Nebraska - Lincoln

Center for Brain, Biology and Behavior: Papers \&

Publications

Brain, Biology and Behavior, Center for

3-16-2011

Neuromagnetic measures of word processing in bilinguals and monolinguals

Yingying Wang

Jing Xiang

Jennifer Vannest

Tom Holroyd

Daria Narmoneva

See next page for additional authors

Follow this and additional works at: https://digitalcommons.unl.edu/cbbbpapers

Part of the Behavior and Behavior Mechanisms Commons, Nervous System Commons, Other Analytical, Diagnostic and Therapeutic Techniques and Equipment Commons, Other Neuroscience and Neurobiology Commons, Other Psychiatry and Psychology Commons, Rehabilitation and Therapy Commons, and the Sports Sciences Commons

This Article is brought to you for free and open access by the Brain, Biology and Behavior, Center for at DigitalCommons@University of Nebraska - Lincoln. It has been accepted for inclusion in Center for Brain, Biology and Behavior: Papers \& Publications by an authorized administrator of DigitalCommons@University of Nebraska - Lincoln. 


\section{Authors}

Yingying Wang, Jing Xiang, Jennifer Vannest, Tom Holroyd, Daria Narmoneva, Paul Horn, Yinhong Liu, Douglas Rose, Ton deGrauw, and Scott Holland 


\title{
Neuromagnetic measures of word processing in bilinguals and monolinguals
}

\author{
Yingying Wang a,b,c,*, Jing Xiang ${ }^{\text {b }}$, Jennifer Vannest ${ }^{\text {b,c }}$, Tom Holroyd ${ }^{\text {d }}$, Daria Narmoneva ${ }^{\text {a }}$, Paul Horn ${ }^{\text {b,e }}$, \\ Yinhong Liu ${ }^{\mathrm{f}}$, Douglas Rose ${ }^{\mathrm{b}}$, Ton deGrauw ${ }^{\mathrm{b}}$, Scott Holland ${ }^{\mathrm{c}}$ \\ ${ }^{a}$ Department of Biomedical Engineering, University of Cincinnati, Cincinnati, OH, United States \\ ${ }^{\mathrm{b}}$ Division of Neurology, Cincinnati Children's Hospital Medical Center, Cincinnati, OH, United States \\ 'Pediatric Neuroimaging Research Consortium, Cincinnati Children's Hospital Research Foundation, Cincinnati, OH, United States \\ ${ }^{\mathrm{d}}$ MEG Core Facility, National Institute of Mental Health, Bethesda, MD, United States \\ e Department of Mathematical Sciences, University of Cincinnati, Cincinnati, OH, United States \\ ${ }^{\mathrm{f}}$ Department of Neurology, Beijing Hospital, Ministry of Health, Beijing, China
}

\section{A R T I C L E I N F O}

\section{Article history:}

Accepted 8 February 2011

Available online 16 March 2011

\section{Keywords:}

Magnetoencephalography

Word processing

Bilinguals

Monolinguals

Frequency

Oscillation

\section{H I G H L I G H T S}

- This is the first MEG study to investigate the spatio-temporal and frequency characteristics between bilinguals and monolinguals during a word-match paradigm.

- Mandarin-English bilingual speakers show stronger beta-band power suppression in the right supramarginal area when processing Mandarin.

- Results are potentially beneficial in determining language lateralization in epilepsy surgical candidates who are bilingual speakers.

\section{A B S T R A C T}

Objective: This study aimed to use magnetoencephalography (MEG) to examine the question of whether Mandarin-English bilingual speakers recruit the same cortical areas or develop distinct language-specific networks without overlaps for word processing.

Methods: Eight healthy Mandarin-English bilingual adults and eight healthy English monolingual adults were scanned while single-word paradigms were audio-visually presented.

Results: Our results showed significantly stronger beta-band power suppression in the right inferior parietal lobe (IPL) covering the supramarginal gyrus (BA 40) and angular gyrus (BA 39) for bilinguals when processing Mandarin versus English. Moreover, there were no significant differences between bilinguals and monolinguals in the left inferior frontal cortex (LIFC, BA 44/45) when both were processing their first language.

Conclusions: These results support the view that Mandarin-English bilinguals have a shared neural system for word processing in both the first and second language, which is highly similar to monolinguals', but with stronger right hemisphere involvement.

Significance: To our knowledge, this is the first MEG study to investigate the spatio-temporal and frequency characteristics between bilinguals and monolinguals, which provides us a new angle to better understand the language system in bilinguals' and monolingual's brain.

(C) 2011 International Federation of Clinical Neurophysiology. Published by Elsevier Ireland Ltd. All rights

reserved.

\section{Introduction}

Bilingual speakers have the ability to comprehend and process both first (L1) and second languages (L2). A fundamental question is whether bilingual speakers use one common neural system for both languages or two distinct neural systems, one for each language, which has led to a number of behavioral psycholinguistic studies (de Groot et al., 2002; Gollan and Kroll, 2001; van Hell

* Corresponding author at: MLC 5033, 3333 Burnet Avenue, Cincinnati, OH 45229-3039, United State. Tel.: +1 513636 3495; fax: +1 5136363754 .

E-mail address: yingying.wang@cchmc.org (Y. Wang). and de Groot, 2003) and functional imaging studies in the past decades. A positron emission tomography (PET) study (Klein et al., 1995) found activations in the left inferior frontal cortex (LIFC) and posterior dorsolateral frontal cortex for French-English bilinguals while they preformed three types of lexical searches. Later, Klein et al. (1999) used a noun-verb generation task in both L1 and L2 for Mandarin-English bilinguals, and they observed activations in the left ventrolateral frontal cortex, posterior dorsolateral, and medial frontal cortex. These two early PET studies showed there are considerable overlaps in the frontal activations, irrespective of whether the task involved L1 or L2. These findings suggest that common neural substrates are involved in processing both 
L1 and L2 even for such contrasting languages as Mandarin and English. Similarly, a functional magnetic resonance imaging (fMRI) study (Kim et al., 1997) showed there are overlapping areas of activations for L1 and L2 in both Broca's and Wernicke's area of the left hemisphere when both languages were acquired early ('early' bilinguals who acquired two languages simultaneously and early in their development) during a sentence-generation task. However, they found spatial separation of L1 and L2 in Broca's area when L2 was acquired in adulthood ('late' bilinguals who acquired conversational fluency in their second languages as young adults), which suggests a distinct neural system for processing L1 and L2 in 'late' bilinguals. Several other studies (Chee et al., 2000; Halsband, 2006; Halsband et al., 2002; Klein et al., 2006) have shown that L1 and L2 partially share neuro-anatomical regions though there are different activation patterns in Broca's area (BA 44/45) and Wernicke's areas (angular/supramarginal gyri).

Decades of research have advanced our knowledge of how bilinguals process words in their dual lexicons and how words are processed differently in their brain (Rastatter and Scukanec, 1990; Rodriguez-Fornells et al., 2006; van Hell and de Groot, 1998). It is well known that bilinguals have differentiated dual lexicons. For example, bilinguals produce a word in L2 resulting in activation of a conceptual system that involves the lexical context of the word not only in L2 but also in L1. In addition, the ability to select the correct word for bilinguals suggests the existence of cognitive control processes (Wagner et al., 2004). Some researchers have shown that words in L1 and L2 are stored in separate lexical memory systems (Keatley et al., 1994), while others suggested the existence of one combined lexico-semantic store that is similar to that in monolinguals (Dijkstra and van Heuven, 2002; Green, 1998; Kroll and Stewart, 1994). Although previous studies contributed a great deal to the further understanding of bilingualism compared to monolingualism, a fundamental debate continues in various aspects such as whether the neural substrates for L1 and L2 in bilinguals overlap or not, whether the lexical and semantic representation in bilinguals are shared or distinct, and whether the mechanisms of language control in bilinguals are general or specific.

The rapid development of functional imaging techniques has opened a fascinating new window to investigate the neural activity of high-level cognitive functions such as language processing for which no animal models exist. The most important recent functional neuroimaging techniques fall into two broad classes, based upon haemodynamic (PET and fMRI) and electrophysiological (EEG and MEG) measures, respectively. These functional imaging techniques have provided a new source of information on bilingual language processing (Klein et al., 2006; Kovelman et al., 2008; Liu and Perfetti, 2003; Wang et al., 2007). As part of a growing field of neurophysiological technique, MEG is increasingly being used in language studies. It provides excellent temporal resolution on the order of $1 \mathrm{~ms}$ (Hämäläinen et al., 1993) and uses an array of highly sensitive superconducting quantum interference device (SQUID) sensors to directly and noninvasively record the magnetic fields associated with electrical activity in the brain. In addition to its excellent temporal resolution, it also offers a new angle for researchers to investigate various kinds of evoked or induced rhythms in the brain (Basar and Schurmann, 1996; Bullock, 1992). Brain oscillations are found in EEG or MEG studies of many mammals while they perform different cognitive tasks (Caplan et al., 2001; Crone et al., 2006; Jacobs et al., 2007; Murthy and Fetz, 1992; Wang et al., 2008; Xiang et al., 2004). The decreases of power in specific frequency band are termed event-related desynchronization (ERD) which may be due to a decrease in synchrony of the underlying neuronal populations, whereas the increases of power in specific frequency band are termed event-related synchronization (ERS) which may be due to a increase in synchrony of the underlying neuronal populations (Pfurtscheller and Lopes da Silva, 1999). Dalal et al. has reported high gamma $(50-150 \mathrm{~Hz})$ and alpha/beta (9-25 Hz) band modulations in epileptic patients during attentive reading using both simultaneous MEG and intracranial electroencephalography (iEEG) recordings (Dalal et al., 2009). Another MEG study showed stronger alpha and beta band suppression over the right precentral gyrus during motor imagery of left hand movements (de Lange et al., 2008). The current understanding of frequency specific cortical oscillations is that they reflect synchronous activity of firing neurons and may be associated with various cognitive functions such as attention and memory (Jensen et al., 2007). However, the functional role of different frequency bands still remains unclear. Using MEG, it has become possible to investigate transient neural oscillations in the complex and distributed cognitive networks and to quantify the frequency signatures of neuronal oscillations in various cortical regions, which could significantly influence our understanding of neuronal processing in both local and distributed networks engaged in complex cognitive functions.

In this study, we used a 275-channel whole head MEG system to measure the neural activity in the brains of proficient Mandarin-English bilinguals and English monolinguals while participants performed a word matching task. We intended to engage both auditory and visual related language networks in order to maximize stimulation to the language areas using a cross-modal audio-visual type of paradigm mentioned in our previous studies (Liu et al., 2008; Wang et al., 2008). Eight adult Mandarin-English bilingual participants who began learning English around age nine, but who consider themselves more proficient in their native Mandarin, read and heard a concrete noun at the same time and they were to press a button if the visually presented noun and auditorily presented noun did not match. Each language was presented separately in a counterbalanced block design and there was a three-minute interval between blocks. Before each block, the bilingual participant was informed which language was to be presented in order to avoid any possibility of initiating a language switching mode. Eight adult English monolingual participants performed the same task only in English. Thus, our experimental design allowed us to not only investigate neural organization in word processing for bilinguals while they are processing in one language mode (Chinese-only) versus in the other (English-only), but also to directly compare word processing between bilinguals and monolinguals while they are performing the same language task.

We also apply an advanced data analysis approach for this study, a beamformer algorithm known as synthetic aperture magnetometry (SAM) (Robinson and Vrba, 1999; van Veen et al., 1997; Vrba and Robinson, 2001) to localize sources of activity in the brain. SAM is an adaptive minimum-variance beamformer for which the output is a weighted linear sum of all the primary MEG sensors. SAM can reveal power changes of the MEG data in specific frequency bands without estimating the number of source locations, which is not available with an equivalent current dipole (ECD) (Hillebrand et al., 2005) method. Although source estimation from MEG data is ill-posed because of the under-determined inverse problem, SAM has been shown to produce results that are consistent with intracranial recordings of local field potentials (Gallen et al., 1995; Oshino et al., 2007). Also some studies have suggested that SAM results are spatially coincident with BOLD responses (Hillebrand et al., 2005; Singh et al., 2002). Moreover, SAM results can be superimposed on anatomical MRI to generate a magnetic source image (MSI) (Williamson et al., 1991) that provides both structural and functional information about the brain.

To the best of our knowledge, our study is the first to investigate the spatio-temporal and frequency differences of word processing between bilinguals and monolinguals using MEG and SAM, which 
can provide new insights into how bilinguals process two languages in one brain.

\section{Methods}

\subsection{Participants}

Eight healthy, right-handed (Oldfield, 1971) Mandarin-English bilinguals (age: $34.3 \pm 6.76$, mean \pm SD) and eight English monolinguals (age: $33.8 \pm 11.8$, mean $\pm \mathrm{SD}$ ) volunteered after having given informed consent according to the Institutional Review Board at Cincinnati Children's Hospital Medical Center (CCHMC). None of the participants had any neurological impairment or neurological trauma. They all had normal or corrected-to-normal vision and normal hearing. A survey on the bilinguals' English learning experience showed that the mean age when they started to learn L2 (English) was about nine years old ( $9 \pm 0.76$, mean \pm SD). English proficiency was evaluated by a standard Test of English as Foreign Language (TOEFL) $(590 \pm 25$, mean \pm SD) (see Table $1)$.

\subsection{Tasks}

The stimuli consisted of two groups of words: 120 concrete English and 120 concrete Chinese words that referred to tangible objects. All the concrete English words were selected from the MRC Psycholinguistic Database (Coltheart, 1981) and were composed of 3-8 letters with 572 as the average concreteness rating and 5 as the average Kucera-Francis written frequency. All the concrete Chinese words were selected from The Contemporary Chinese Dictionary and composed of 2 Chinese characters. All the acoustic English words were recorded by a professional linguist from CCHMC and the Chinese words were recorded by a professional neurologist from China in a recording studio of the Department of Audiology at CCHMC.

The English and Chinese words were used in two conditions, respectively. The words in each condition were presented in a randomized order. The two conditions were performed in a counterbalanced order across the bilingual participants, and there was a three-minute interval between the two. Before each condition, bilingual participants would be informed of what was going to be presented (Chinese-only or English-only) so that the recruitment of language switching behavioral and neural mechanisms could be avoided. For monolingual participants, an English-only condition was presented. The inter-stimulus interval for both conditions was randomized from 2400 to $2600 \mathrm{~ms}$ so that the stimulus onset could not be predicted. All the participants were instructed to press a response key using their right index finger if the visual and auditory word presentation did not match (i.e. one word was seen while a different word was heard). No response was required when the visual and auditory stimuli matched. Overall, 20 English words and 20 Chinese words were presented with a mismatch between the visual and auditory presentation in each condition, respectively. One hundred trials of match condition were used for MEG data analysis and 20 trials of mismatch condition were excluded. All the words were presented visually as white letters on a black background with duration of $2000 \mathrm{~ms}$ and the onsets of the visual and auditory stimuli were aligned, while the length of auditory word stimuli were $900 \pm 40 \mathrm{~ms}$ (mean $\pm \mathrm{SD}$ ). Word presentation and response recording were accomplished with BrainX software (Xiang et al., 2001).

\subsection{MEG data acquisition}

We used a 275-channel whole head MEG system (VSM MedTech Ltd., Port Coquitlam, BC, Canada) to record all the data in a magnetically shielded room (MSR) (Vacuum-Schmelze, Hanau, Germany) that was designed to reduce environmental magnetic noise. For each participant, three coils were placed on the nasion and at the left and right pre-auricular points before data acquisition commenced, so that the position of the sensor array with respect to the nasion-ear MEG head coordinate system could be measured. The MEG data were recorded at a sampling rate of $6000 \mathrm{~Hz}$ with online noise cancellation using third-order gradient balancing and without any online band-pass filters. There was a three minute break between the two tasks for bilingual participants, and participants could relax and adjust their head position during the break. All the participants were instructed to avoid eye blinks and head movements during the recording procedure.

All the participants had their MRI scans at CCHMC (1.5 T Sigma scanner, GE Medical Systems, Milwaukee, WI). T1-weighted axial anatomical images with an in-plane resolution of $256 \times 256$ and 128 slices (1.4 mm thickness) were recorded. Three fiducial points

Table 1

Participant information.

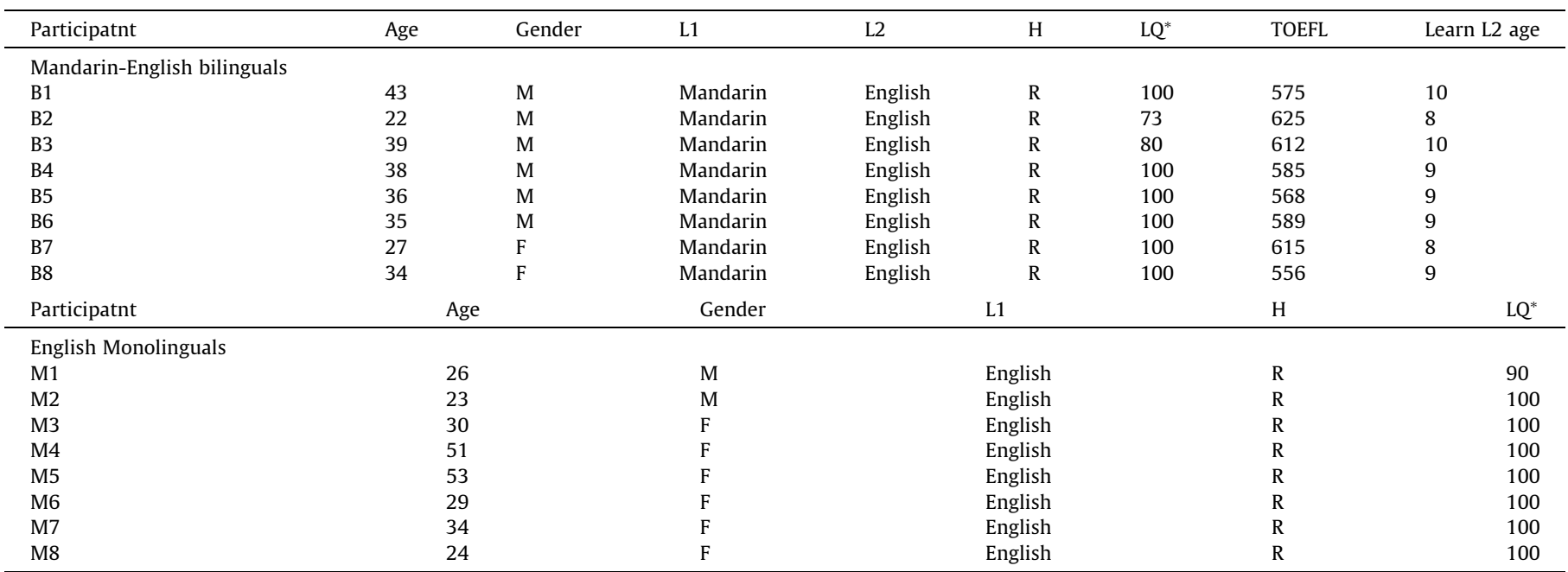

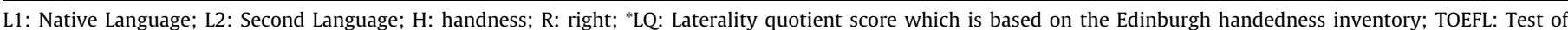
English as Foreign Language (TOEFL); TOEFL > 550 means proficiency in English (L2). 
were placed in identical locations as the ones used in the MEG recordings so that 3D MRI and MEG data could be co-registered precisely to yield a MSI using these three landmarks.

\subsection{MEG data processing}

At the sensor level, MEG waveforms were manually averaged using DataEditor (VSM MedTech Ltd., Port Coquitlam, BC, Canada) for identification of temporal components after the removal of eyeblinks, muscular activity and sensor jumps using the artifact rejection routines implemented in Fieldtrip, an open-source Matlab toolbox (http://fieldtrip.fcdonders.nl/). The averaged MEG data were preprocessed by removing the baseline offset based on the pre-stimulus interval. An off-line low pass filter $(30 \mathrm{~Hz})$ and high pass filter $(1 \mathrm{~Hz})$ were applied for viewing. The latencies and amplitudes of each recognizable peak were recorded for each participant.

SAM was used for localization of cortical electrical source activity from the MEG data. SAM creates a spatial filter for estimating source activity from the MEG data, and it computes the forward solution for the magnetic field due to a current dipole in a homogeneously conducting sphere using the Sarvas equation (Sarvas, 1987). Since SAM minimizes all unwanted signals, the estimated source waveforms will not be contaminated by unwanted magnetic artifacts (electrical interference, magnetocardiogram, and eye blinks). In addition, it has been shown that MEG is able to detect signals from deep brain structures such as hippocampus and amygdala using evoked field or SAM methods (Ioannides et al., 1995; Luo et al., 2007). There is a fundamental limitation of SAM in that perfectly correlated sources appear non-dipolar and cannot be detected by the beamformer. However, the two sources would have to maintain perfect correlation over the entire course of the experiment to be invisible (van Veen et al., 1997). Before doing SAM analysis, a multiple local sphere head model was created for each participant based on their own anatomical 3D-MRI using analysis of functional neuroimages (AFNI) (http://www.afni.nimh.nih.gov/) (Cox, 1996). To determine the frequency bands of interest, frequency analysis was performed at the sensor level using the Curry software (Version 6.0.16, Compumedics Neuroscan, Singen, Germany). Two frequency bands, beta $(12-30 \mathrm{~Hz})$ and low gamma $(30-50 \mathrm{~Hz})$, were chosen for SAM analysis. It is very possible that there are power increases in the beta-band $(12-30 \mathrm{~Hz})$ accompanied simultaneously by power decreases in low gammaband $(30-50 \mathrm{~Hz})$. If a frequency range included both beta and low gamma-band signals, the total spectrum power changes would be less. Hence, the precise selection of frequency band could enhance contrast in SAM results. Then, SAM was applied to estimate the cortical source power integrated over the specified time windows for both beta-band and low gamma-band in $5 \mathrm{~mm}$ steps across the volume. At each coordinate $\theta$, the SAM beamformer coefficients $W_{\theta}$ were computed from the covariance $C$ of the unaveraged MEG data and the lead field $B_{\theta}$ (Robinson, 2004) using the equation: $W_{\theta}=\frac{C^{-1} B_{\theta}}{B_{\theta}^{T} C^{-1} B_{\theta}}$, where $C$ is the covariance matrix of the MEG data, and $B$ is the forward solution for a unit current dipole with parameters $\theta$. In order to capture the dynamic spatiotemporal activity in the brain, we applied a sliding window method (Cornwell et al., 2007). With a window length of $250 \mathrm{~ms}$ and a step of $50 \mathrm{~ms}$, we estimated the signal power in each voxel $(5 \times 5 \times$ $5 \mathrm{~mm}$ ) by using dual-state (active versus control state) SAM (pseudo-F), which computes the ratio of source powers between the active and control states $\left(F^{2}=\frac{\sum_{i=1}^{N_{A}} S_{A i}^{2}}{\sum_{i=1}^{N} S_{C i}^{2}}\right.$, where the subscripts $A$ and $C$ represents the active and control state, respectively, $S_{A i}$ and $S_{C i}$ stand for active and control source power, respectively). The control state used as a baseline was the $250 \mathrm{~ms}$ before stimu- lus onset and the active state was the $250 \mathrm{~ms}$ window sliding with a $50 \mathrm{~ms}$ step after stimulus onset. SAM results were superimposed with 3D-MRIs and visualized using in-house software called magnetic source locator (MSL) (Xiang et al., 2001).

According to the SAM results, the MEG data were further analyzed using a virtual sensor approach with four regions of interest (ROIs) per hemisphere including IFC (BA 44/45), superior temporal gyrus (STG) (BA 22), precuneus (BA 7), and inferior parietal lobe (IPL) (BA 40). ROIs were defined on the basis of statistically significant activations among BC (bilinguals doing Chinese word task), $\mathrm{BE}$ (bilinguals doing English word task), and ME (monolinguals doing English word task). The coordinates $(x, y, z)$ of a virtual sensor were based on the local maxima of each ROI. For each virtual sensor, a weight vector was calculated. This weight vector was then applied to the MEG sensor data and to estimate the source waveform from the virtual sensor, given by the equation: $\widehat{S}_{\theta}(k)=W_{\theta}^{T} M(k)$, where $\widehat{S}_{\theta}(k)$ is projected source estimate for specified target $\theta, M(k)$ is the measurement signal-space vector at sample $k$. Then, the time series of the virtual sensor in the ROIs were used for calculation of time-frequency representation (TFRs) using the Morlet wavelet function of the Time-Frequency Toolbox ( $\mathrm{Au}-$ ger et al., 1996). The source waveform $S(t)$ was filtered into small frequency ranges using a digital band-pass filter and then the wavelet coefficients $W_{s}\left(\tau, f_{c}\right)$, which are complex numbers, were computed as a function of time, $\tau$, and center frequency of each band, $f_{c}$, from $W_{s}\left(\tau, f_{c}\right)=\int_{-\infty}^{\infty} S(t) \Psi_{\tau, f_{c}}^{*}(u) d u$, where $\Psi_{\tau, f_{c}}^{*}(u)$ is the complex conjugate of the Morlet wavelet defined by $\Psi_{\tau \cdot f_{c}}(u)=$ $\sqrt{f_{c}} e^{i 2 \pi f_{c}(u-\tau)} e^{-\frac{(u-\tau)^{2}}{2 \sigma^{2}}}$ which is the product of a sinusoidal wave with a Gaussian probability density. For a given time and frequency, $\Psi_{\tau, f_{c}}^{*}(u)$ is a function only of $\sigma$, the standard deviation of the Gaussian density function, which determines how many cycles of the wavelet are to be used. Importantly, there is a trade-off between frequency resolution and time resolution. The wavelet function has a poor time and good frequency resolution at low frequencies, while it has a good time and poor frequency resolution at high frequencies. Taking this trade-off into consideration, we used fewer cycles of the wavelet for lower frequencies (e.g., 4 cycles for $20 \mathrm{~Hz}$ ) and more cycles for higher frequencies (e.g., 8 cycles for $40 \mathrm{~Hz}$ ).

\subsection{Statistical analyses}

The latencies and amplitudes of M1-M6 were statistically compared among $\mathrm{BC}, \mathrm{BE}$, and $\mathrm{ME}$ using a nonparametric procedure, the Wilcoxon Signed-Rank test, which requires fewer assumptions (e.g., an underlying Normal or Gaussian distribution for data) than a parametric procedure like the paired Student's $t$-test. Statistical analyses were performed using SAS version 9.1 for Windows (SAS Institute Inc., Cary, NC, USA).

For group analysis of SAM results, the anatomical 3D-MRIs of each participant were first spatially normalized and transformed to the common Talairach daemon (Lancaster et al., 2000) using AFNI. Then, the SAM results, expressed in the individual head coordinate system, were also transformed to the Talairach space. Then, we performed a one sample $t$-test on the SAM results on a voxel by voxel basis at each time window to determine which brain regions showed significantly different increases or decreases in power between active (task) and control (rest) states for BC, BE, and $\mathrm{ME}$, respectively. We also compared the activation regions of $B C$ versus $\mathrm{BE}, \mathrm{BC}$ versus $\mathrm{ME}$, and $\mathrm{BE}$ versus $\mathrm{ME}$ using two sample $t$-test. To control for multiple comparisons, statistically significant effects were tested with false discovery rate (FDR) (Genovese et al., 2002). The threshold was set at $p<.01$ which corresponded to $|t|>3.50$ for the one sample $t$-test and at $p<.0001$ which corre- 
(a)

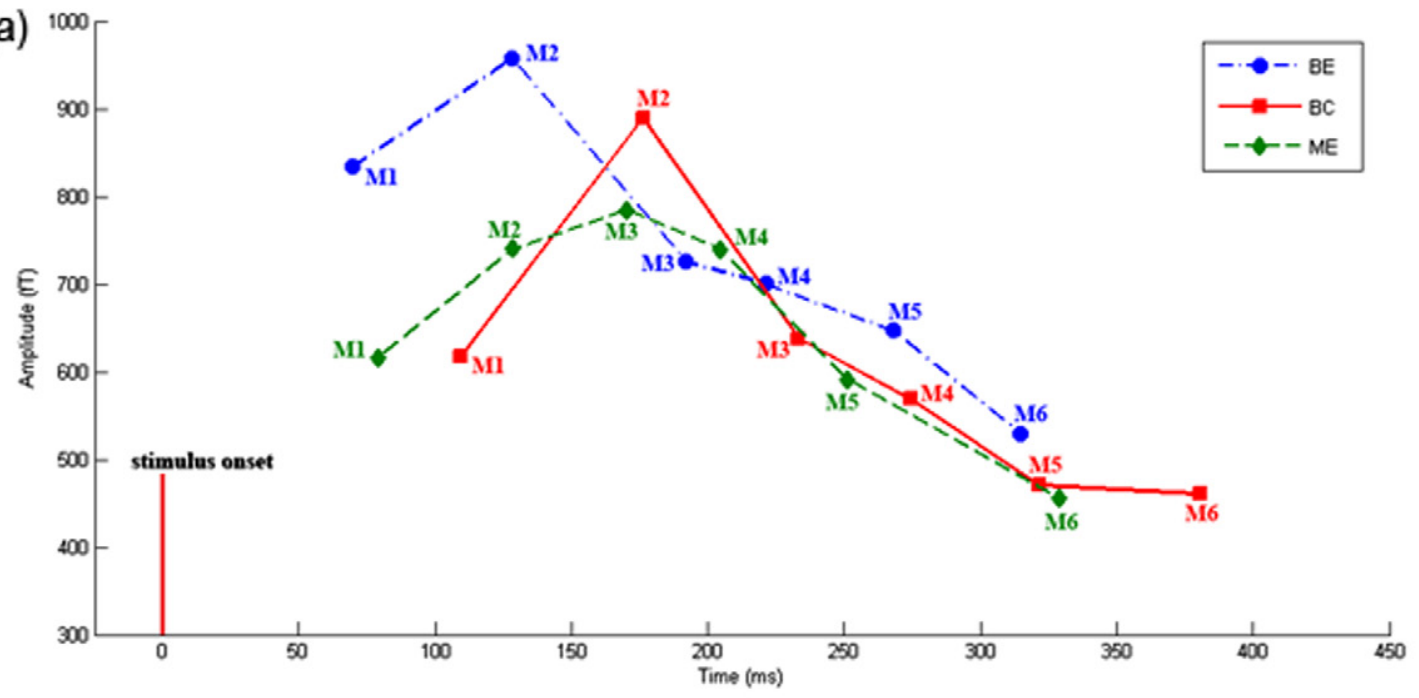

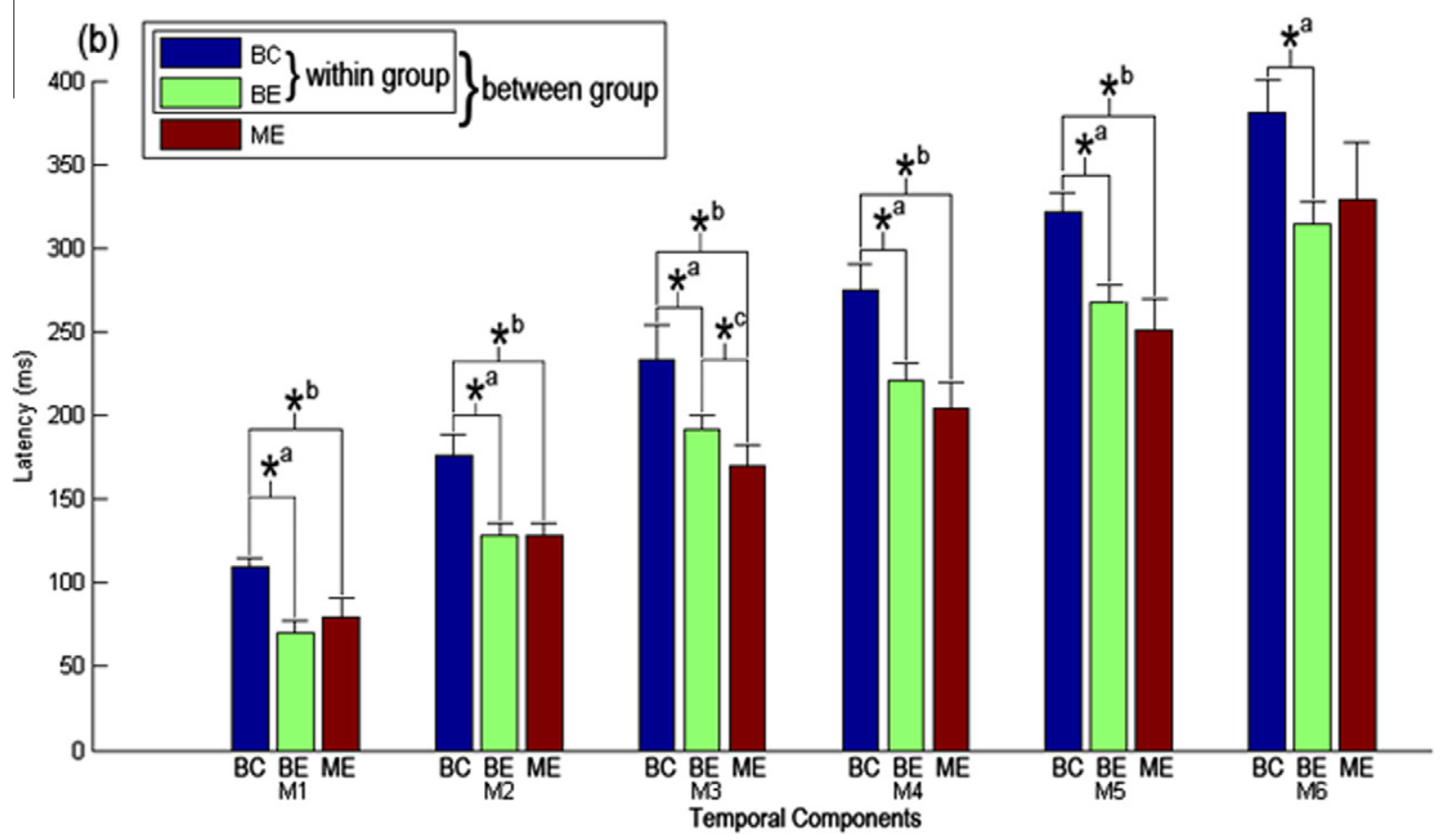

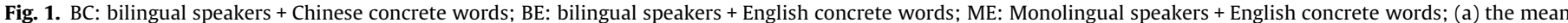

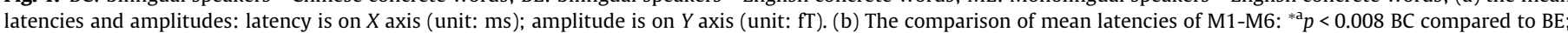
$*^{\mathrm{b}} p<0.008 \mathrm{BC}$ compared to ME; ${ }^{* \mathrm{c}} p<0.008 \mathrm{BE}$ compared to ME.

Table 2

The latencies and amplitudes of the averaged MEG waveform components.

\begin{tabular}{|c|c|c|c|c|c|c|c|}
\hline & & M1 & M2 & M3 & M4 & M5 & M6 \\
\hline \multirow[t]{2}{*}{ BC } & Lat (ms) & $109.55 \pm 4.98^{\mathrm{a}, \mathrm{b}}$ & $176.21 \pm 12.18^{a, b}$ & $233.13 \pm 20.90^{\mathrm{a}, \mathrm{b}}$ & $274.61 \pm 15.76^{\mathrm{a}, \mathrm{b}}$ & $321.61 \pm 12.08^{\mathrm{a}, \mathrm{b}}$ & $380.64 \pm 20.56^{a}$ \\
\hline & Amp (fT) & $618.26 \pm 182.27$ & $889.01 \pm 206.00$ & $637.96 \pm 199.96$ & $568.61 \pm 102.97$ & $470.18 \pm 100.77$ & $460.35 \pm 114.66$ \\
\hline \multirow[t]{2}{*}{ BE } & Lat (ms) & $69.75 \pm 8.20$ & $128.15 \pm 7.61$ & $191.80 \pm 8.82^{\mathrm{c}}$ & $221.19 \pm 10.88$ & $268.04 \pm 10.02$ & $314.55 \pm 12.86$ \\
\hline & Amp (fT) & $833.65 \pm 294.28$ & $956.98 \pm 324.72$ & $725.20 \pm 138.18$ & $700.45 \pm 138.49$ & $646.80 \pm 136.35$ & $529.91 \pm 135.52$ \\
\hline \multirow[t]{2}{*}{ ME } & Lat (ms) & $79.23 \pm 11.97$ & $128.53 \pm 7.05$ & $170.34 \pm 12.49$ & $204.61 \pm 15.04$ & $251.20 \pm 19.71$ & $329.21 \pm 33.86$ \\
\hline & Amp (fT) & $615.93 \pm 179.61$ & $740.18 \pm 200.37$ & $784.13 \pm 265.60$ & $739.71 \pm 252.43$ & $591.65 \pm 237.94$ & $455.08 \pm 140.15$ \\
\hline
\end{tabular}

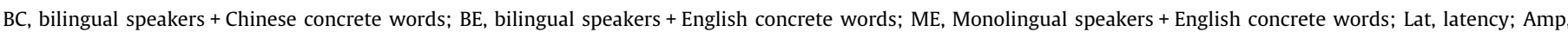
amplitude. The data are presented as (mean \pm Standard Deviation).

a $p<0.008 \mathrm{BC}$ compared to BE.

b $p<0.008 \mathrm{BC}$ compared to ME

c $p<0.008 \mathrm{BE}$ compared to ME. 
Table 3

\begin{tabular}{|c|c|c|c|c|c|c|c|c|c|c|c|c|c|c|c|c|c|}
\hline \multirow[t]{2}{*}{ Locations } & \multirow[t]{2}{*}{ BA } & \multirow[t]{2}{*}{$\mathrm{H}$} & $\begin{array}{l}\text { Peak time }(\mathrm{ms}) \text { and } \\
\text { frequency band }(\mathrm{Hz})\end{array}$ & $x$ & $y$ & $z$ & $|t|$ & $\begin{array}{l}\text { Peak time }(\mathrm{ms}) \text { and } \\
\text { frequency band }(\mathrm{Hz})\end{array}$ & $x$ & $y$ & $z$ & $|t|$ & $\begin{array}{l}\text { Peak time }(\mathrm{ms}) \text { and } \\
\text { frequency band }(\mathrm{Hz})\end{array}$ & $x$ & $y$ & $z$ & $|t|$ \\
\hline & & & \multicolumn{5}{|l|}{ BC (Task vs. Rest) } & \multicolumn{5}{|l|}{ BE (Task vs. Rest) } & \multicolumn{5}{|l|}{ ME (Task vs. Rest) } \\
\hline \multicolumn{18}{|l|}{ Occipito-temporal } \\
\hline Fusiform gyrus & 37 & $\mathrm{~L}$ & $200-450,12-30$ & -51 & -58 & -12 & 4.91 & $50-300,12-30$ & -37 & -68 & -11 & 5.48 & $50-300,30-50$ & -47 & -62 & -17 & 4.28 \\
\hline Cuneus & & $\mathrm{L}$ & $100-350,30-50$ & -23 & -84 & 12 & 5.29 & $250-500,12-30$ & -13 & -84 & 28 & 6.24 & $250-500,30-50$ & -10 & -69 & 9 & 6.45 \\
\hline Inferior temporal gyrus & 20 & $\mathrm{~L}$ & $200-450,12-30$ & -52 & -56 & -12 & 4.91 & $300-550,30-50$ & -50 & -59 & -8 & 4.45 & & & & & \\
\hline Lingual gyrus & $18 / 17$ & $\mathrm{~L}$ & $300-550,12-30$ & -16 & -91 & -11 & 4.70 & $250-500,12-30$ & -4 & -83 & -2 & 5.97 & $150-400,12-30$ & -3 & -89 & -3 & 12.38 \\
\hline Middle temporal gyrus & 21 & $\mathrm{~L}$ & $200-450,12-30$ & -56 & -23 & -12 & 4.63 & $350-600,12-30$ & -54 & -50 & -7 & 4.76 & $300-550,12-30$ & -58 & -3 & -3 & 9.02 \\
\hline Middle occipital gyrus & 19 & $\mathrm{~L}$ & $150-400,30-50$ & -22 & -84 & 16 & 5.12 & $50-300,30-50$ & -50 & -62 & -3 & 5.84 & $250-500,12-30$ & -30 & -67 & 9 & 7.21 \\
\hline Precuneus & 7 & $\mathrm{~L}$ & $400-650,12-30$ & -15 & -62 & 23 & 4.62 & $250-500,12-30$ & -4 & -67 & 45 & 7.32 & $200-450,12-30$ & -2 & -59 & 33 & 4.19 \\
\hline Fusiform gyrus & 37 & $\mathrm{R}$ & $200-450,12-30$ & 41 & -41 & -14 & 5.92 & $450-700,30-50$ & 52 & -49 & -17 & 4.08 & $350-600,12-30$ & 36 & -48 & -7 & 7.17 \\
\hline Cuneus & & $\mathrm{R}$ & $200-450,30-50$ & 17 & -83 & 7 & 4.76 & $300-550,30-50$ & 3 & -69 & 12 & 5.46 & $150-400,30-50$ & 5 & -92 & 3 & 7.25 \\
\hline Inferior temporal gyrus & & $\mathrm{R}$ & $300-550,12-30$ & 56 & -37 & -17 & 6.45 & & & & & & & & & & \\
\hline Lingual gyrus & 18 & $\mathrm{R}$ & $250-500,12-30$ & 30 & -76 & -5 & 5.69 & $300-550,12-30$ & 14 & -82 & -11 & 5.20 & $200-450,30-50$ & 18 & -86 & 14 & 6.41 \\
\hline Middle temporal gyrus & $21 / 39$ & $\mathrm{R}$ & $200-450,12-30$ & 62 & -26 & -1 & 5.55 & $100-350,30-50$ & 41 & -62 & 28 & 4.74 & $150-400,30-50$ & 37 & -53 & 21 & 4.89 \\
\hline Precuneus & 7 & $\mathrm{R}$ & $350-600,12-30$ & 20 & -65 & 32 & 5.66 & $300-550,30-50$ & 5 & -59 & 47 & 7.27 & $150-400,12-30$ & 5 & -60 & 43 & 5.01 \\
\hline Middle occipital gyrus & $18 / 19$ & $\mathrm{R}$ & $50-300,12-30$ & 30 & -83 & -8 & 9.46 & $350-600,12-30$ & 42 & -69 & 8 & 4.06 & $200-450,30-50$ & 18 & -86 & 14 & 6.41 \\
\hline \multicolumn{18}{|l|}{ Temporal and parietal } \\
\hline Superior temporal gyrus & 22 & $\mathrm{~L}$ & $250-500,12-30$ & -53 & -9 & -2 & 4.50 & $400-650,12-30$ & -53 & -57 & 18 & 4.17 & $50-300,12-30$ & -59 & -35 & 18 & 7.69 \\
\hline Inferior parietal lobe & 40 & $\mathrm{~L}$ & $200-450,12-30$ & -53 & -32 & 23 & 6.17 & $100-350,12-30$ & -62 & -24 & 27 & 4.77 & $300-550,12-30$ & -48 & -32 & 47 & 11.38 \\
\hline Superior temporal gyrus & 22 & $\mathrm{R}$ & $400-650,12-30$ & 48 & -3 & 1 & 5.70 & $200-450,30-50$ & 57 & 6 & 3 & 4.05 & $300-550,12-30$ & 48 & -5 & 3 & 4.55 \\
\hline Inferior parietal lobe & 40 & $\mathrm{R}$ & $100-350,12-30$ & 47 & -43 & 42 & 4.61 & $0-250,30-50$ & 52 & -33 & 28 & 4.2 & & & & & \\
\hline \multicolumn{18}{|l|}{ Frontal } \\
\hline Cingualte cortex & $32 / 29$ & $\mathrm{~L}$ & $200-450,30-50$ & -9 & 37 & 17 & 7.16 & $350-600,30-50$ & -3 & -42 & 18 & 4.52 & $450-700,30-50$ & -2 & 20 & 35 & 5.57 \\
\hline Precentral cortex & 4 & $\mathrm{~L}$ & $350-600,12-30$ & -43 & -13 & 48 & 4.62 & & & & & & $300-550,12-30$ & -58 & -3 & 22 & 10.99 \\
\hline Precentral cortex & 5 & $\mathrm{~L}$ & $400-650,30-50$ & -3 & -37 & 52 & 4.38 & & & & & & & & & & \\
\hline Precentral cortex & 6 & $\mathrm{~L}$ & $100-350,12-30$ & -56 & 3 & 18 & 5.56 & $200-450,12-30$ & -47 & -3 & 39 & 5.09 & $200-450,12-30$ & -54 & 0 & 27 & 5.43 \\
\hline Precentral cortex & 9 & $\mathrm{~L}$ & & & & & & $200-450,30-50$ & -43 & 21 & 37 & 6.30 & & & & & \\
\hline Prefrontal cortex & 6 & $\mathrm{~L}$ & $100-350,30-50$ & -18 & 36 & 38 & 6.49 & $250-500,30-50$ & -33 & 6 & 50 & 6.77 & $250-500,30-50$ & -28 & 6 & 45 & 5.17 \\
\hline Insula & 13 & $\mathrm{~L}$ & $200-450,12-30$ & -42 & 0 & 12 & 5.61 & $200-450,12-30$ & -42 & 1 & 13 & 4.38 & $250-500,12-30$ & -34 & 7 & 12 & 5.14 \\
\hline Inferior frontal gyrus & 44 & $\mathrm{~L}$ & $200-450,12-30$ & -45 & -1 & 9 & 6.53 & $150-400,12-30$ & -50 & 0 & 21 & 4.13 & $300-550,12-30$ & -53 & 3 & 19 & 6.76 \\
\hline Cingualte cortex & $32 / 29$ & $\mathrm{R}$ & $100-350,30-50$ & 11 & 19 & 38 & 5.82 & $450-700,30-50$ & 8 & -50 & 8 & 4.53 & $450-700,30-50$ & 5 & 20 & 35 & 5.98 \\
\hline Prefrontal cortex & 6 & $\mathrm{R}$ & & & & & & $200-450,30-50$ & 29 & -4 & 52 & 7.06 & $300-550,12-30$ & 58 & -3 & 13 & 6.34 \\
\hline Prefrontal cortex & 6 & $\mathrm{R}$ & $100-350,30-50$ & 11 & 16 & 47 & 8.87 & $250-500,12-30$ & 26 & -8 & 46 & 5.18 & $400-650,30-50$ & 26 & 0 & 46 & 4.72 \\
\hline Insula & 13 & $\mathrm{R}$ & $150-400,12-30$ & 41 & -9 & 3 & 5.23 & $250-500,12-30$ & 42 & -8 & 18 & 6.59 & $250-500,30-50$ & 29 & -13 & 11 & 7.33 \\
\hline Inferior frontal gyrus & 44 & $\mathrm{R}$ & $200-450,12-30$ & 47 & 0 & 9 & 4.69 & $350-600,12-30$ & 54 & 11 & 12 & 5.39 & & & & & \\
\hline
\end{tabular}

$\mathrm{BC}$, bilingual speakers + Chinese concrete words; BE, bilingual speakers + English concrete words; ME, Monolingual speakers + English concrete words; BA, brodmann area; $\mathrm{H}$, hemisphere; $p<0.01,|t|>3.50$. 
sponded to $|t|>3.94$ for the two sample $t$-test. $P$ values were corrected as determined by FDR threshold $q<.05$ using 3dFDR component of AFNI.

\section{Results}

\subsection{Temporal components}

All participants accurately identified the mismatches (minimum accuracy criterion: 90\%) during the scan, which demonstrated that all participants were engaged during the MEG data recording. The averaged MEG waveform showed six main temporal components across all participants. We refer to the six peaks as M1, M2, M3, M4, M5, and M6 (see Fig. 1 and Table 2). Fig. 1a shows the mean amplitudes and latencies of the peaks for BC, BE, and ME, and Table 2 presents a descriptive statistical summary. There was no significant difference in amplitude among BC, BE, and ME. However, we noticed that the latencies of M1-M6 for the BC group were significantly later than the $\mathrm{BE}$ group, while the latencies of M1-M5 for the BC group were significantly later than the ME group. In addition, only the latency of M3 for the BE group was significantly later than the ME group.

\subsection{Source locations}

We observed a number of similar and a few distinct patterns of activation in the brain among $\mathrm{BC}, \mathrm{BE}$, and ME. There were considerable overlaps in the classic language area (i.e. Broca's and Wernicke's area) and other regions (see Table 3), although the peak locations are slightly different. In Table 3, we itemized the regions of significant power changes comparing the task state to the rest state for BC, BE, and ME, respectively. Peak means the activation was at the highest level. The significance threshold was set to $p<.01(|t|>3.50)$.

\section{Task versus rest}

As we expected, BC, BE, and ME all showed significant betaband ERD (power decrease) in the occipito-temporal cortex covering occipital lobe (including BA 7/17/18/19 and cuneus) and temporal lobe (including BA 20/21/37/39), which were corresponding to our audio-visually presented word stimuli. After the word was audio-visually presented on the projector, participants need to retrieval lexical meaning of the word and make a right decision if the audio and visual stimuli were the same. In order to achieve a correct decision, the cingulate cortex (CC) showed gamma-band ERS (power increase) (including BA 24/29/32) with a little spatial separation among BC, BE, and ME (see Table 3). Then, we observed significant beta-band ERD in a network of frontal regions including a large cluster in the inferior frontal cortex (IFC) (BA 43/44/45), the precentral cortex (BA 4/6), and the prefrontal cortex (BA 6/9/10) among $B C, B E$, and $M E$, which suggested the strong role of these regions in word processing in both English and Chinese.

Despite the considerable overlaps in the regions activated during the word processing task among $\mathrm{BC}, \mathrm{BE}$, and $\mathrm{ME}$, we also noticed several distinct activation patterns. The $B C$ group produced significant beta-band ERD in bilateral IFC (BA 44) (left < right, in other words more beta-band ERD on the right), while the BE group had significant beta-band ERD in bilateral IFC (BA 44/45) (left >right), and the ME group only showed beta-band ERD in the LIFC (BA 44). Furthermore, Mandarin-English bilingual participants showed significant beta-band ERD in the left Wernicke's area (BA 40) and gamma-band ERS in the right Wernicke's area when processing either L1 or L2, whereas the ME group only showed signif- icant beta-band ERD in the left Wernicke's area (BA 40). These findings indicated a strong left lateralized pattern in the Broca's area (BA 44) and Wernicke's areas (BA 40) for English monolingual speakers.

\section{Within the group, $B C$ versus $B E$}

The two sample $t$-test (paired) between BC and BE (two sided tail $p=0.0001$ at $t=3.94$ ) showed significantly stronger gammaband ERS (see Fig. 2) in the LIFC (BA 44/45/47) and beta-band ERD in the left anterior cingulate cortex (ACC) for bilinguals when processing their native language (Mandarin), while we also observed significantly stronger beta-band ERD in the right insula (BA 13), the right medial frontal gyrus (BA 6), and the right IFC (BA 47) for bilinguals when processing L2 versus L1.

\section{Between the groups, $\mathrm{BC}$ versus $\mathrm{ME}$}

The two sample $t$-test (unpaired) between BC and ME (two sided tail $p=0.0001$ at $t=3.94$ ) showed significantly stronger gamma-band ERS (see Fig. 2) in the right Wernicke's area (angular/ supramarginal gyrus, BA 39/40), the left CC including ACC and PCC, and left medial frontal gyrus (BA 6) for bilinguals than for monolinguals when both were processing their own L1. Moreover, there was significantly beta-band ERD in both the right precentral gyrus (BA 6) and the left supramarginal gyrus (BA 40). A left lateralized activation pattern in LIFC (BA 44) was consistent between BC and ME. However, the right Broca's area (BA 44) displayed stronger beta-band ERD under the significance threshold $p<0.001$ $(|t|>3.32$, uncorrected) for bilinguals processing L1 (Chinese) versus monolinguals processing L1 (English), which could indicate Mandarin-English bilinguals have higher engagement of both hemispheres when processing their L1, whereas monolinguals display a strong left lateralized activation pattern when processing their L1.

\section{Between the groups, BE versus ME}

The two sample t-test (unpaired) between $\mathrm{BE}$ and ME (two sided tail $p=0.0001$ at $t=3.94$ ) showed significantly stronger gamma-band ERS (see Fig. 2) in the right Wernicke's area (angular gyrus, BA 39), the right insula (BA 13), and the right thalamus, as well as the right CC and the right medial frontal gyrus (BA 6), which illustrated a stronger right hemisphere involvement for bilinguals versus monolinguals when they were doing the same word task in English. In addition, there were beta-band ERD in some other cortical regions including LIFC (BA 44), left inferior parietal lobe and left medial frontal gyrus (BA 10), which indicated English monolinguals had higher left hemisphere involvement than Mandarin-English bilinguals did when both were processing English.

\subsection{Frequency spectrum characteristics}

Virtual sensor time series were created for four source regions per hemisphere including IFC (BA 44/45), superior temporal gyrus (STG) (BA 22), precuneus (BA 7), and inferior parietal lobe (IPL) (BA 40). ROIs were defined on the basis of statistically significant activations among $\mathrm{BC}, \mathrm{BE}$ and $\mathrm{ME}$ (task versus rest) under significant threshold $p<.01$. The coordinates $(x, y, z)$ were gained based on the local maxima of each ROI (see Fig. 3). When the waveform of virtual sensor showed a flat line, it indicates there is no activation in that ROI. The two ROIs including the right BA 44 and the right BA 40 showed flat waveform of virtual sensor for ME. All other six ROIs presented waveforms for the virtual sensors among BC, BE, and ME. Importantly, there was no change of lateralization in LIFC 


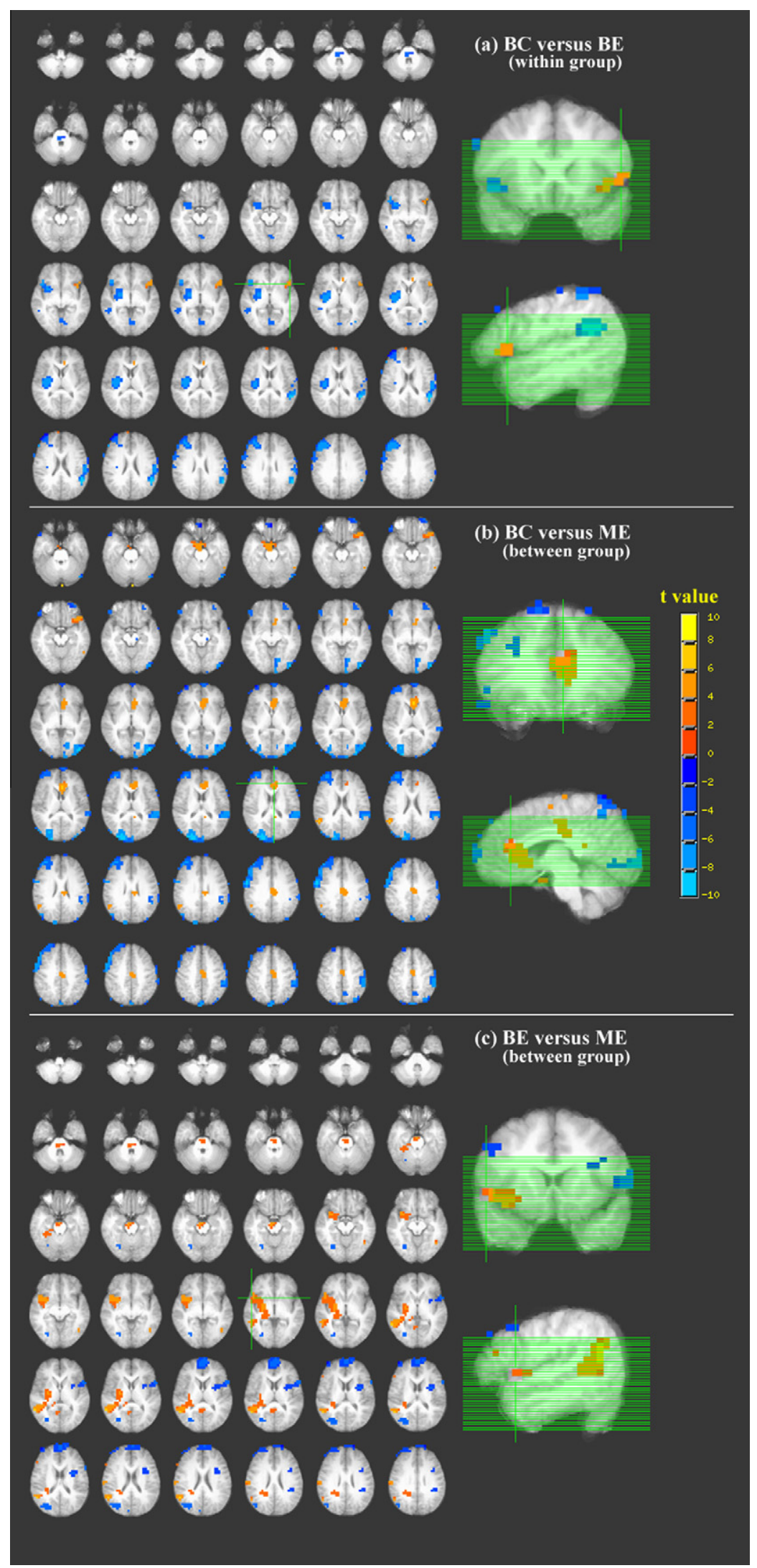

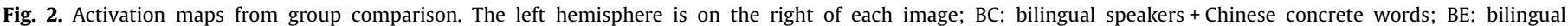
speakers + English concrete words; ME: Monolingual speakers + English concrete words; Significance threshold set $p<0.0001$ corresponding to $|t|>3.94$.

(BA 44), which may indicate that LIFC is a common cortical area involved in word processing, irrespective of whether the word task was in L1 or L2 and whether the participant was bilingual or monolingual. However, there was greater involvement of right hemi- 


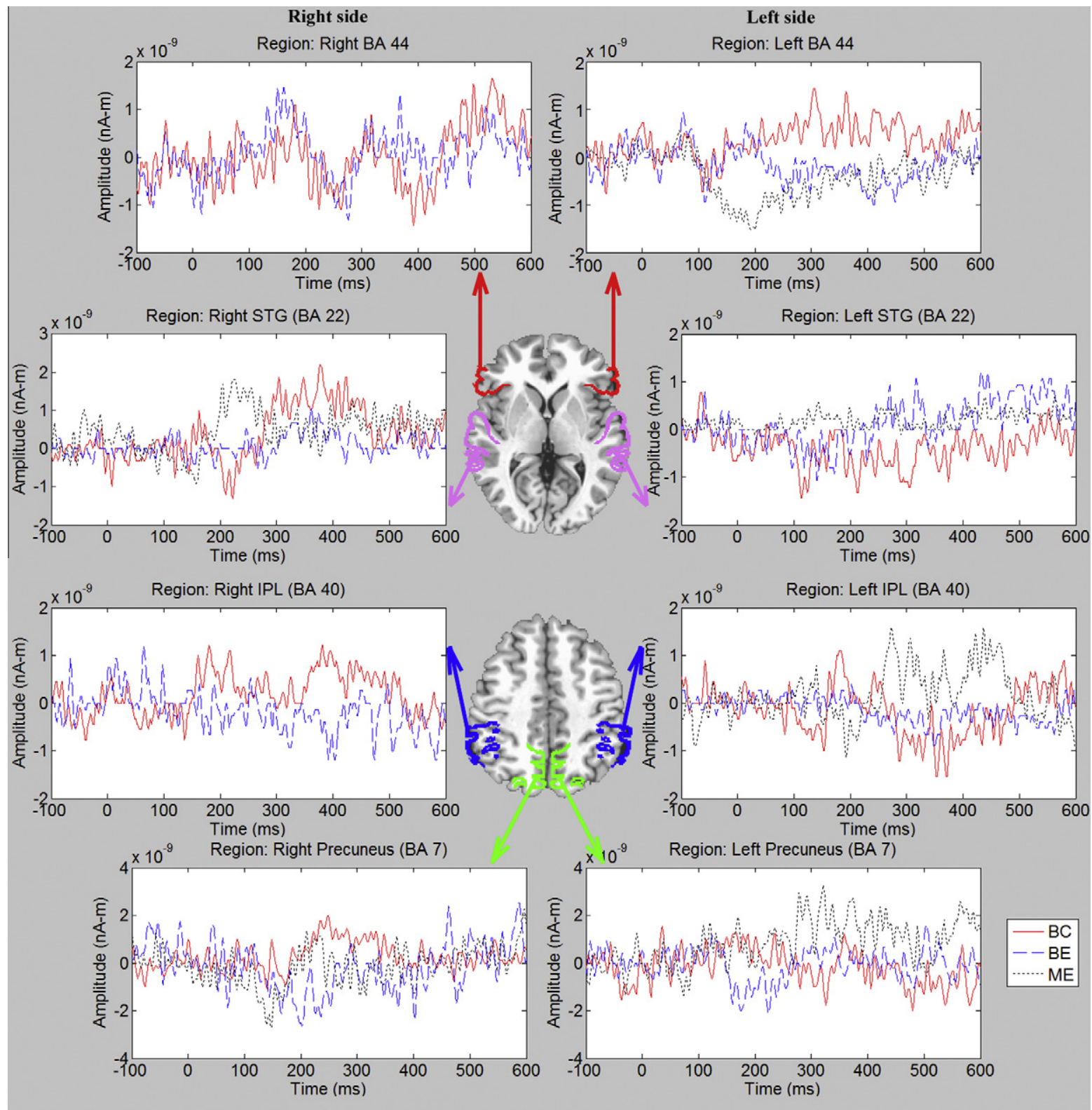

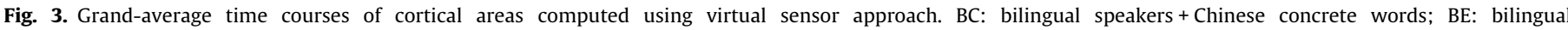

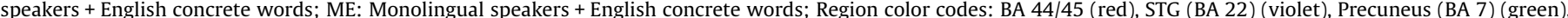

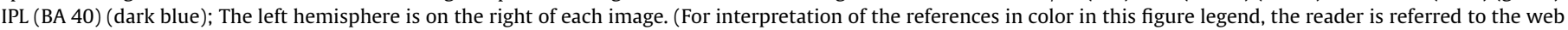
version of this article.)

sphere in Wernicke's areas (BA 39/40) for Mandarin-English bilinguals than for English monolinguals, which is consistent with previous research (Mildner, 1999). In addition, we observed a delay of the peak latency between bilinguals processing L1/L2 and monolinguals, which agreed with our results from the physical sensor level (see Table 3).

To further investigate the characteristics of time and frequency alternations among BC, BE, and ME, the TFRs of each waveform in each ROI were constructed to represent simultaneously time and frequency information (see Fig. 4). In the time-frequency plots, the frequency spectrum was given for each time step using Morlet wavelets in order to demonstrate the evolution of the frequencies, which could potentially add more information to our understanding of how brain oscillations in bilinguals differ from that in monolinguals when both are processing audio-visually presented words. In Fig. 4, we noticed that the onset of higher beta-band power was later for bilinguals ( $\mathrm{BC}$ and $\mathrm{BE}$ ) compared to monoling- uals (ME). In the LIFC (BA 44) where no lateralization change was observed, we found low gamma-band power increases around $350 \mathrm{~ms}$ for BC, but not for BE or ME. In the STG (BA 22), there were greater power changes in the left side than the right side. In addition, bilinguals showed stronger power changes in the right IPL than in the left IPL, which might indicate a stronger right hemisphere involvement in bilingual speakers. Furthermore, there were stronger beta- and low gamma-band oscillations in the left precuneus for the $\mathrm{BC}$ group than for the $\mathrm{BE}$ or ME group, whereas there were similar beta-band brain oscillations in the right precuneus around $200 \mathrm{~ms}$ for $\mathrm{BC}, \mathrm{BE}$, and $\mathrm{ME}$.

\section{Discussion}

Within the group, bilingual speakers processed only one language at one time rather than switching between L1 and L2 since our focus is the linguistic system involved during a single word 


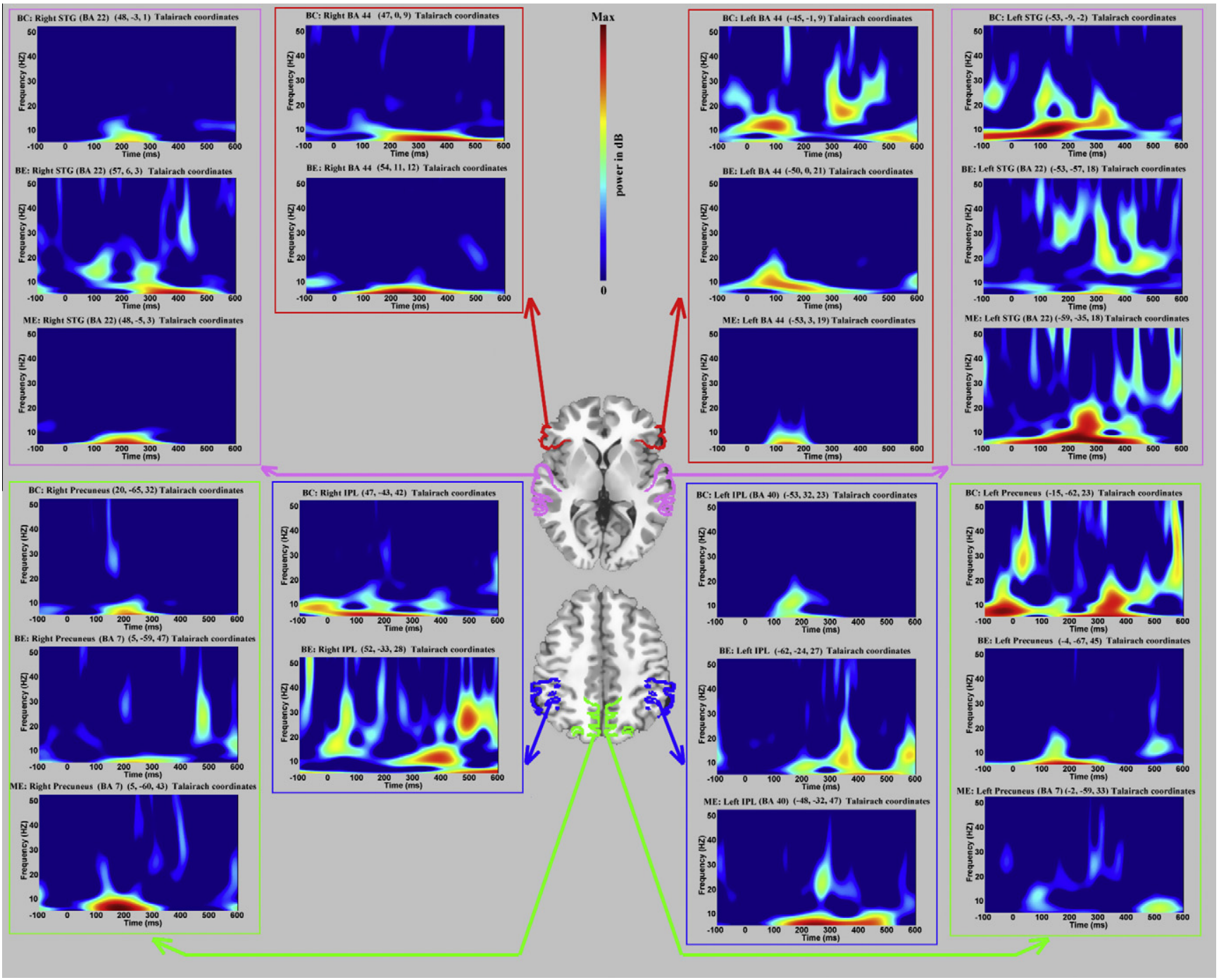

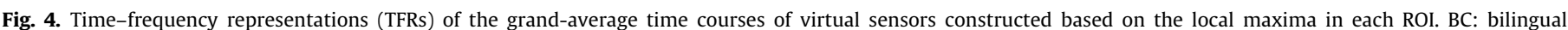

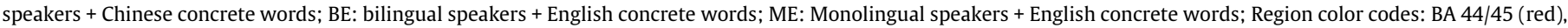

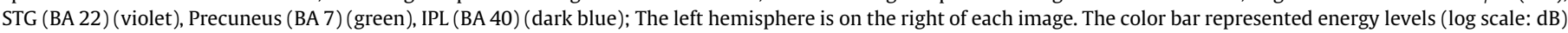
of the frequency band.

processing task in L1 and L2 rather than the switching mechanism between L1 and L2. Our results fit well in recent models of language control during bilingual processing (Abutalebi et al., 2009) where the LIFC and ACC may indicate that L1 was in need to be controlled better while the right prefrontal activity may indicate that there is inhibition of L1 during L2 processing (Dijkstra and van Heuven, 2002). In addition, different activation patterns were presented between L1 and L2, which agree with previous neuroimaging studies (Cao et al., 2009; Kovelman et al., 2008; Xue et al., 2006). Those differences were expected because of the great differences between logographic Chinese and alphabetical English. Chinese characters consist of a number of strokes, so that the encoding of Chinese words might activate some regions (i.e. the right inferior temporal gyrus) involved in the integration of orthographic and phonologic information. In addition, the great involvement of some regions in right hemisphere can be due to the tonal aspects of Chinese language. Chinese is a tonal language, so Mandarin-English bilingual speakers tend to recruit more regions in right hemisphere to process Chinese than English.

Between the groups, there were no significant differences between bilinguals and monolinguals in the LIFC (BA 44/45) when they were processing their own native language, while there were significantly stronger activations in the LIFC (BA 44/45) for monolinguals than bilinguals when both were processing the same language (English). These findings indicate that bilinguals process their L1 in a similar manner to the way monolinguals process their L1, but with some distinct activation patterns, such as high involvement in the right supramarginal gyrus (BA 40) of the parietal lobe, which might be due to the differences between Chinese and English (Xue et al., 2006), for example because Chinese characters consist of a number of strokes which originated from pictographs and remain logographic (Siok and Fletcher, 2001). Our results in IFC (BA 44/45) with no change in lateralization are consistent with previous studies (Xue et al., 2006, 2004). However, our results of lateralization in other cortical areas (i.e. Wernicke's area) are different from a previous study (Xue et al., 2006). They found strong leftward asymmetry in parietal BA 40 for bilinguals performing either semantic or phonological tasks in L1, whereas we found strong rightward (i.e. right > left) asymmetry in parietal BA 40 for bilinguals processing L1 words at a single word level. This might be due to the difference between experimental tasks. Their tasks were more focused on the examination of the cerebral asymmetry of Chinese character processing using the visual modality, while our tasks used audiovisual (audio and visual modalities) 
matched or mis-matched single word stimuli (Wang et al., 2008) in order to investigate the whole process of encoding, retrieving, comparing and responding. Our finding of the high engagement of Wernicke's area (BA 39/40) in the right parietal lobe is consistent with several other previous studies (Cheung et al., 2006; Valaki et al., 2004).

\subsection{Temporal components}

We found six temporal components (M1-M6) (see Table 2) in $\mathrm{BC}, \mathrm{BE}$, and ME, which agrees with previous ERP studies (Khateb et al., 2007; Liu and Perfetti, 2003). Our findings indicated that it took a longer time for bilinguals to process their L1 than L2, while it took a shorter time for monolinguals to process their L1 than for bilinguals to process their L1. As we expected, these differences might be due to the different properties of Chinese and English. The encoding of audio-visually presented Chinese words takes longer time than that of English words. Furthermore, only the M3 component showed a significantly shorter latency for monolinguals than for bilinguals when both were processing English. Interestingly, there seems to be less delay in the temporal components between bilinguals and monolinguals when the same language task was used, which might indicate that bilinguals develop a differential language specific network which consist of both overlapped and distinct cortical areas in the brain. These results indicate that there is a shared neural system of word processing between bilingual and monolingual brains, but with a language specific network in bilingual brain.

\subsection{Source locations}

For $\mathrm{BC}, \mathrm{BE}$ and $\mathrm{ME}$, comparing the task state to the rest state, we found highly similar significant activation patterns $(p<.01$, see Table 2 ) in primary visual cortex (BA 17/18), visual association cortex including middle occipital gyrus (BA 19) and precuneus (BA 7), and bilateral DLPFC (BA 6/9/10), STG (BA 22) and classic language areas including Broca's area (BA 44/45) and Wernicke's area (39/40). Importantly, though bilinguals (BC and $\mathrm{BE}$ ) and monolinguals (ME) activated highly similar cortical areas in the left hemisphere, there were spatial separations in the right hemisphere including the right BA 44 and the BA 39/40 where only Mandarin-English bilingual speakers showed significant activations when processing L1/L2.

Our group comparison results among BC, BE, and ME showed that there are overlapping and distinct cortical areas involved in word processing between bilingual speakers (BC, BE) and monolingual speakers (ME). Moreover, bilinguals produced significantly $(p<.0001)$ stronger activations in BA 39/40 of the right hemisphere than English monolinguals when both were processing their L1, whereas monolinguals showed significantly stronger activations in the IFC (BA 44/45) of the left hemisphere than bilinguals when both were processing English. This might be due to the high engagement of the right hemispheric regions in bilinguals which reduced the work load in the LIFC (BA 44/45). Overall, our results are consistent with some previous studies (Chee et al., 2000; Halsband, 2006; Halsband et al., 2002; Klein et al., 1995), showing that there were some shared and distinct cortical areas for both L1 and L2 within the bilingual group and between the language groups.

\subsection{Frequency spectrum characteristics}

To the best of our knowledge, few studies have used MEG to investigate the frequency spectrum characteristics and directly compared brain oscillations during single word processing in healthy and highly proficient bilinguals versus monolinguals. Some previous studies have reported brain oscillations in beta- and low gamma-band (Caplan et al., 2001; Gunji et al., 2007; Medvedev,
2001) associated with perception and cognition. Our results suggested that both beta- and low gamma-band frequency activity work together during word processing for most ROIs, and they co-exist with different temporal resolution. For example, in the left precuneus of the $\mathrm{BC}$ group, there were strong low gamma-band oscillations around $50-300 \mathrm{~ms}$ and beta-band oscillations around 350-600 ms. Interestingly, precuneus activations have been reported to be presented in visual and auditory presentation modalities and for memory retrieval of words (Halsband, 2006; Halsband et al., 2002). In addition, Chinese word processing compared to English word processing was associated with greater power spectrum changes in left BA 44, left STG and left precuneus, and left insula, which is a possible inference that Chinese character meaning is more difficult to access (Chee et al., 2000).

This is the first study to examine the difference between bilinguals and monolinguals when processing single words using the MEG technique. This study showed very interesting results and indicated that there are similar and distinct brain regions involved in word processing for $\mathrm{BC}, \mathrm{BE}$, and ME. The spatial-temporal and frequency information from this study added another dimension to our understanding of bilingualism and monolingualism which may provide novel insights into the language impairments of bilingual patients (i.e. temporal lobe epilepsy, stroke). For example, the non-invasive MEG technique could benefit the determination of language lateralization in epilepsy surgical candidates who are bilingual speakers. Since this study was conducted in United States, a monolingual Mandarin speaker comparison group and EnglishMandarin bilinguals was difficult to recruit. Otherwise, it would be interesting to compare brain activations between MandarinEnglish bilinguals and Mandarin monolinguals during L1 (Chinese) processing. In summary, the present study broadens the understanding of spatio-temporal and frequency differences between bilinguals and monolinguals using modern MEG techniques. It also provides insights into the degree of separation in spatio-temporal and frequency domains of the language system within the bilingual group and between groups.

\section{Acknowledgements}

This study was supported by a Trustee Grant to Dr. Jing Xiang from Cincinnati Children's Hospital Medical Centre, Cincinnati, OH, USA. We would like to thank Dr. David Brown for his help in audio recording and Ms. Akhila Rajagopal for her help in statistical analysis. Also we would like to thank Mr. Kendall O'Brien for his technical help in performing all the MRI scans.

\section{References}

Abutalebi J, Rosa PA, Tettamanti M, Green DW, Cappa SF. Bilingual aphasia and language control: a follow-up fMRI and intrinsic connectivity study. Brain Lang 2009;109:141-56.

Auger F, Flandrin P, Gonçalvès P, Lemoine O. Time-frequency toolbox tutorial. CNRS (France) and Rice University (USA); 1996.

Basar E, Schurmann M. Alpha rhythms in the brain: functional correlates. News Physiol Sci 1996;11:90-6.

Bullock TH. Introduction to induced rhythms: a widespread, heterogeneous class of oscillations. In: Baar E, Bullock TH, editors. Induced rhythms in the brain. Boston: Birkhäuser; 1992. p. 1-26.

Cao F, Peng D, Liu L, Jin Z, Fan N, Deng Y, et al. Developmental differences of neurocognitive networks for phonological and semantic processing in Chinese word reading. Hum Brain Mapp 2009;30:797-809.

Caplan JB, Madsen JR, Raghavachari S, Kahana MJ. Distinct patterns of brain oscillations underlie two basic parameters of human maze learning. J Neurophysiol 2001;86:368.

Chee MW, Weekes B, Lee KM, Soon CS, Schreiber A, Hoon JJ, et al Overlap and dissociation of semantic processing of Chinese characters, English words, and pictures: evidence from fMRI. NeuroImage 2000;12:392-403.

Cheung MC, Chan AS, Chan YL, Lam JM. Language lateralization of Chinese-English bilingual patients with temporal lobe epilepsy: a functional MRI study. Neuropsychology 2006;20:589-97.

Coltheart M. The MRC psycho-linguistic database. QJ Exp Psychol-A 1981:497-505 
Cornwell BR, Baas JM, Johnson L, Holroyd T, Carver FW, Lissek S, et al. Neura responses to auditory stimulus deviance under threat of electric shock revealed by spatially-filtered magnetoencephalography. NeuroImage 2007;37:282-9.

Cox RW. AFNI: software for analysis and visualization of functional magnetic resonance neuroimages. Comput Biomed Res 1996;29:162-73.

Crone NE, Sinai A, Korzeniewska A. High-frequency gamma oscillations and human brain mapping with electrocorticography. Prog Brain Res 2006;159:275-95.

Dalal SS, Baillet S, Adam C, Ducorps A, Schwartz D, Jerbi K, et al. Simultaneous MEG and intracranial EEG recordings during attentive reading. Neurolmage 2009; 45:1289-304.

de Groot A, Borgwaldt S, Bos M, van den Eijnden E. Lexical decision and word naming in bilinguals: language effects and task effects* 1. J Mem Lang 2002;47:91-124.

de Lange FP, Jensen O, Bauer M, Toni I. Interactions between posterior gamma and frontal alpha/beta oscillations during imagined actions. Front Hum Neurosci $2008 \cdot 2: 7$

Dijkstra T, van Heuven WJB. The architecture of the bilingual word recognition system: from identification to decision. Biling-Lang Cogn 2002;5:175-97.

Gallen CC, Schwartz BJ, Bucholz RD, Malik G, Barkley GL, Smith J, et al. Presurgical localization of functional cortex using magnetic source imaging. J Neurosurg 1995;82:988-94.

Genovese CR, Lazar NA, Nichols T. Thresholding of statistical maps in functiona neuroimaging using the false discovery rate $* 1$. Neurolmage $2002 \cdot 15: 870-8$.

Gollan TH, Kroll JF. Bilingual lexical access. In: Callahan CD, Macciocchi SN, editors. The handbook of cognitive neuropsychology: what deficits reveal about the human mind. Baltimore: Psychology Press; 2001. p. 321-45.

Green DW. Mental control of the bilingual lexico-semantic system. Biling-Lang Cogn 1998;1:67-81.

Gunji A, Ishii R, Chau W, Kakigi R, Pantev C. Rhythmic brain activities related to singing in humans. Neurolmage 2007;34:426-34.

Halsband U. Bilingual and multilingual language processing. J Physiol Paris 2006;99:355-69.

Halsband U, Krause BJ, Sipila H, Teras M, Laihinen A. PET studies on the memory processing of word pairs in bilingual Finnish-English subjects. Behav Brain Res 2002;132:47-57

Hämäläinen $\mathrm{M}$, Hari R, Ilmoniemi RJ, Knuutila J, Lounasmaa OV. Magentoencephalography-theory, instrumentation, and applications to noninvasive studies of the working human brain. Rev Mod Phys 1993:413-97.

Hillebrand A, Singh KD, Holliday IE, Furlong PL, Barnes GR. A new approach to neuroimaging with magnetoencephalography. Hum Brain Mapp 2005;25:199-211.

Ioannides AA, Liu MJ, Liu LC, Bamidis PD, Hellstrand E, Stephan KM. Magnetic field tomography of cortical and deep processes: examples of "real-time mapping" of averaged and single trial MEG signals. Int J Psychophysiol 1995;20:161-75.

Jacobs J, Kahana MJ, Ekstrom AD, Fried I. Brain oscillations control timing of singleneuron activity in humans. J Neurosci 2007;27:3839-44.

Jensen $\mathrm{O}$, Kaiser J, Lachaux JP. Human gamma-frequency oscillations associated with attention and memory. Trends Neurosci 2007:30:317-24.

Keatley CW, Spinks JA, De Gelder B. Asymmetrical cross-language priming effects. Mem Cogn 1994;22:70-84

Khateb A, Abutalebi J, Michel CM, Pegna AJ, Lee-Jahnke H, Annoni JM. Language selection in bilinguals: a spatio-temporal analysis of electric brain activity. Int Psychophysiol 2007;65:201-13.

Kim KH, Relkin NR, Lee KM, Hirsch J. Distinct cortical areas associated with native and second languages. Nature 1997;388:171-4.

Klein D, Milner B, Zatorre RJ, Meyer E, Evans AC. The neural substrates underlying word generation: a bilingual functional-imaging study. Proc Natl Acad Sci USA 1995;92:2899-903.

Klein D, Milner B, Zatorre RJ, Zhao V, Nikelski J. Cerebral organization in bilinguals: a PET study of Chinese-English verb generation. Neuroreport 1999;10:2841-6.

Klein D, Zatorre RJ, Chen JK, Milner B, Crane J, Belin P, et al. Bilingual brain organization: a functional magnetic resonance adaptation study. NeuroImage 2006;31:366-75

Kovelman I, Baker SA, Petitto LA. Bilingual and monolingual brains compared: a functional magnetic resonance imaging investigation of syntactic processing and possible "neural signature" of bilingualism. J Cogn Neurosci 2008;20:153-69.

Kroll JF, Stewart E. Category interference in translation and picture naming: evidence for asymmetric connections between bilingual memory representations. J Mem Lang 1994;33:149-74.

Lancaster JL, Woldorff MG, Parsons LM, Liotti M, Freitas CS, Rainey L, et al. Automated Talairach atlas labels for functional brain mapping. Hum Brain Mapp 2000;10:120-31.
Liu Y, Perfetti CA. The time course of brain activity in reading English and Chinese: an ERP study of Chinese bilinguals. Hum Brain Mapp 2003:18:167-75.

Liu Y, Xiang J, Wang Y, Vannest JJ, Byars AW, Rose DF. Spatial and frequency differences of neuromagnetic activities in processing concrete and abstract words. Brain Topogr 2008;20:123-9.

Luo Q, Holroyd T, Jones M, Hendler T, Blair J. Neural dynamics for facial threat processing as revealed by gamma band synchronization using MEG. NeuroImage 2007;34:839-47.

Medvedev AV. Temporal binding at gamma frequencies in the brain: paving the way to epilepsy? Australas Phys Eng Sci Med 2001;24:37-48.

Mildner V. Functional cerebral asymmetry for verbal stimuli in a foreign language. Brain Cogn 1999;40:197-201.

Murthy VN, Fetz EE. Coherent 25-35-Hz oscillations in the sensorimotor cortex of awake behaving monkeys. P Natl Acad Sci USA 1992;89:5670.

Oldfield RC. The assessment and analysis of handedness: the Edinburgh inventory. Neuropsychologia 1971:9:97-113.

Oshino S, Kato A, Wakayama A, Taniguchi M, Hirata M, Yoshimine T. Magnetoencephalographic analysis of cortical oscillatory activity in patients with brain tumors: synthetic aperture magnetometry (SAM) functional imaging of delta band activity. NeuroImage 2007;34:957-64

Pfurtscheller G, Lopes da Silva FH. Event-related EEG/MEG synchronization and desynchronization: basic principles. Clin Neurophysiol 1999;110:1842-57.

Rastatter MP, Scukanec G. Evidence for hemispheric specialization of lexical distinctions in bilingual Chinese-Mandarin speakers. Cortex 1990;26:423-32.

Robinson SE. Localization of event-related activity by SAM (erf). Neurol Clin Neurophysiol 2004. p. 109

Robinson SE, Vrba J. Functional neuroimaging by synthetic aperture magnetometry (SAM). Recent Advances in Biomagnetism. Sendai: Tohoku Univ. Press; 1999.

Rodriguez-Fornells A, Balaguer RDD, Münte TF. Executive control in bilingual language processing. Lang Learn 2006;56:133-90.

Sarvas J. Basic mathematical and electromagnetic concepts of the biomagnetic inverse problem. Phys Med Biol 1987;32:11.

Singh KD, Barnes GR, Hillebrand A, Forde EM, Williams AL. Task-related changes in cortical synchronization are spatially coincident with the hemodynamic response. NeuroImage 2002;16:103-14.

Siok WT, Fletcher P. The role of phonological awareness and visual-orthographic skills in Chinese reading acquisition. Dev Psychol 2001;37:886-99.

Valaki CE, Maestu F, Simos PG, Zhang W, Fernandez A, Amo CM, et al. Cortical organization for receptive language functions in Chinese, English, and Spanish: a cross-linguistic MEG study. Neuropsychologia 2004;42:967-79.

van Hell JG, de Groot AMB. Disentangling context availability and concreteness in lexical decision and word translation. Q J Exp Psychol-A 1998;51:41-63.

van Hell JG, de Groot AMB. Conceptual representation in bilingual memory: effects of concreteness and cognate status in word association. Biling-Lang Cogn 2003;1:193-211.

van Veen BD, van Drongelen W, Yuchtman M, Suzuki A. Localization of brain electrical activity via linearly constrained minimum variance spatial filtering. IEEE Trans Biomed Eng 1997;44:867-80.

Vrba J, Robinson SE. Signal processing in magnetoencephalography. Methods $2001 ; 25: 249-71$.

Wagner AD, Bunge SA, Badre D. Cognitive control, semantic memory, and priming: Contributions from prefrontal cortex. In: Gazzaniga MS, editor. The cognitive neurosciences III. Boston: MIT Press; 2004. p. 709-26.

Wang Y, Xiang J, Kotecha R, Vannest J, Liu Y, Rose D, et al. Spatial and frequency differences of neuromagnetic activities between the perception of open- and closed-class words. Brain Topogr 2008;21:75-85.

Wang Y, Xue G, Chen C, Xue F, Dong Q. Neural bases of asymmetric language switching in second-language learners: an ER-fMRI study. NeuroImage 2007;35:862-70.

Williamson SJ, Lü ZL, Karron D, Kaufman L. Advantages and limitations of magnetic source imaging. Brain Topogr 1991;4:169-80.

Xiang J, Holowka S, Chuang S. Spatiotemporal analysis of neuromagnetic activation associated with mirror reading. Neurol Clin Neurophysiol 2004;2004:90-3.

Xiang J, Wilson D, Otsubo H, Ishii R, Chuang S. Neuromagnetic spectral distribution of implicit processing of words. Neuroreport 2001;12:3923-7.

Xue G, Chen C, Jin Z, Dong Q. Cerebral asymmetry in the fusiform areas predicted the efficiency of learning a new writing system. J Cogn Neurosci 2006;18:923-31.

Xue G, Dong Q, Jin Z, Zhang L, Wang Y. An fMRI study with semantic access in low proficiency second language learners. Neuroreport 2004;15:791-6. 